$$
\text { http://dx.doi.org/10.12819/2022.19.1. } 4
$$

WZB

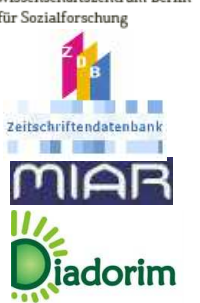

\title{
Comunicação e Saúde: Uma Análise Comunicacional do Enfrentamento do Zika Vírus por Potenciais Gestantes do Distrito Federal e Entorno
}

\section{Communication and Health: A Communication Analysis of the Zika Virus Coping with Potential Pregnant Women in the Federal District and Surrounding Areas}

Lorena Braga de Siqueira Mestrado em Educação pela Universidade de Brasília Graduada em Jornalismo pela Universidade Católica de Brasília

E-mail: lorena.siqueira@a.ucb.br

Robson Borges Dias

Doutorado em Comunicação pela Universidade de Brasília E-mail: rbsn.dias@gmail.com

Luiza Mônica de Assis Silva Doutora em Psicologia Social do Trabalho e das Organizações pela Universidade de Brasília E-mail: luiza.silva@p.ucb.br

Vânia Mara Vasques Balbino de Souza Mestrado em Comunicação pela Universidade Católica de Brasília E-mail: vania.souza@a.ucb.br

Eliane Muniz Lacerda

Mestre em Comunicação pela Universidade de Brasília E-mail: eliane.lacerda@ucb.br

Endereço: Lorena Braga de Siqueira UnB - Brasília, DF, 70910-900, Brasil. Endereço: Robson Borges Dias UnB - Brasília, DF, 70910-900, Brasil. Endereço: Luiza Mônica de Assis Silva UnB - Brasília, DF, 70910-900, Brasil. Endereço: Vânia Mara Vasques Balbino de Souza UnB - Brasília, DF, 70910-900, Brasil. Endereço: Eliane Muniz Lacerda UnB - Brasília, DF, 70910-900, Brasil.
Editor-Chefe: Dr. Tonny Kerley de Alencar Rodrigues

Artigo recebido em 06/09/2021. Última versão recebida em 20/09/2021. Aprovado em 28/09/2021.

Avaliado pelo sistema Triple Review: a) Desk Review pelo Editor-Chefe; e b) Double Blind Review (avaliação cega por dois avaliadores da área).

Revisão: Gramatical, Normativa e de Formatação 


\title{
RESUMO
}

A cobertura midiática sobre a epidemia do Zika vírus (2015-2016) produziu sentidos de alerta, confusão e apreensão, dentre outros. O objetivo deste trabalho é identificar os sentidos compartilhados, em Comunicação e Saúde, tendo como base as informações recebidas por três grupos de mulheres do Distrito Federal e entorno do DF. A pesquisa qualitativa, por meio de entrevista em profundidade, coleta relatos de mulheres que adiaram o plano de ter filhos (1), de mulheres que enfrentaram a doença grávidas (2) e a que teve um bebê com microcefalia (3). Os resultados mostram que mesmo com todo o conteúdo lido, ouvido e ou assistido na televisão, a única fonte confiável de informação eram os médicos. As mídias não influenciaram nas decisões finais da maioria das entrevistadas, mas ajudaram a se sentirem informadas sobre as novidades a respeito do Zika.

Palavras-chave: Comunicação e Saúde. Zika vírus. Jornalismo. Mídia. saúde da mulher.

\begin{abstract}
Media coverage of the Zika virus epidemic (2015-2016) has produced senses of warning, confusion and apprehension, among others. The objective of this work is to identify the shared meanings in Communication and Health based on the information received by three groups of women from the Federal District and surrounding DF. The qualitative research, through an in-depth interview, collected reports of women who postponed the plan to have children (1), women who had faced the disease (2) and had a baby with microcephaly (3). The results show that even with all content read, heard and / or watched on television, doctors were the only reliable source of information. The media did not influence the final decisions of most of the interviewees, but they helped her feel informed about the news about Zika.
\end{abstract}

Keywords: Communication and Health. Zika virus. Journalism. Media. Health Woman. 


\title{
1 INTRODUÇÃO
}

Este trabalho se insere no escopo de Comunicação e Saúde sobre o Zika Vírus, que tem análise bibliométrica de artigos científicos sobre o Zika vírus (MARTINS, 2016), o papel da mídia em meio às emergências (AGUIAR; ARAUJO, 2016), a questão da informação e conhecimento (DINIZ; BRITO, 2016), memória em redes sociais como arquivos relacionados ao Zika vírus (ANTUNES; ALVES; GOVEIA; OLIVEIRA; CARDOSO, 2016) e o Zika pela voz das mulheres (NETTO, 2016).

A origem do porquê a comunicação é tão importante para os assuntos de saúde é a de que uma necessita da outra para que exista conhecimento da população a respeito de novas doenças, desenvolvimento de pesquisas, vacinas e evolução de doenças. Essa relação começou quando foi percebido que as pessoas não tinham muito conhecimento sobre higienização e a automedicação (ARAÚJO; CARDOSO, 2007, p. 24). Com isso, se inicia todo o processo de exposição da notícia enquadrada (Agendamento) como pauta de saúde pública e sanitária. E, tendo como foco o público, a recepção: o processo de conscientização da doença, seus riscos e medidas a serem tomadas em termos práticos, da vida privada.

Para esse trabalho, foi analisado o contexto do acesso à informação de saúde durante o final do ano de 2015 quando se teve conhecimento, por meio da mídia, de que uma nova doença estava afetando bebês ainda nas barrigas de suas mães e causando uma má-formação congênita, termo utilizado pelo Ministério da Saúde, que é quando o cérebro não se desenvolve de maneira adequada ${ }^{1}$, a microcefalia.

\begin{abstract}
Ao provocar malformações no feto, a epidemia de Zika acabou associada a uma espécie de epidemia de microcefalia, comumente subnotificada no Brasil. A revelação de que os casos de microcefalia estariam ligados à incidência de Zika trouxe uma dramaticidade maior à doença, principalmente, pelo apelo jornalístico que lhe seguiu. Com isso, na memória do dizer, o vírus Zika passou a ser associado diretamente à gravidez principalmente pelos riscos que impunha (ANTUNES; ALVES; GOVEIA; OLIVEIRA; CARDOSO, 2016, p. 5 e 6).
\end{abstract}

Uma doença que ocorria em casos raríssimos se torna de repente um alarde, inicialmente, na região do nordeste brasileiro e passando para outras regiões do país. Assim, é apresentado de forma científica o Zika vírus, uma doença transmitida pelo mesmo mosquito

\footnotetext{
${ }^{1}$ Definição retirada do portal do Ministério da Saúde especializada no combate ao mosquito Aedes aegypti: http://combateaedes.saude.gov.br/pt/recomendacoes-as-gestantes/zika-X-microcefalia.

${ }^{3}$ Processo de Impeachment do presidente do país e casos de corrupção.
} 
causador da dengue e da Chikungunya. A partir daí a cobertura midiática começa, em pouco tempo, a bombardear os noticiários com várias informações.

Já no início de 2016 as notícias sobre a nova doença cedem espaço na grande mídia para os Jogos Olímpicos e para a crise política vivida no país ${ }^{3}$. A doença tão falada no final do ano anterior de repente aparece nos noticiários com alguma novidade na área científica, ficando nas pautas de redações apenas como uma segunda opção de produção, enquanto o número de pessoas infectadas e a falta de assistência só aumentam.

O objetivo deste trabalho é analisar como as mulheres se sentiam em relação às informações transmitidas pelos veículos de comunicação, de forma ampla. Isto é, se a partir delas se sentiram completamente informadas a respeito do assunto ou não.

A relevância deste trabalho se justifica pela importância do compromisso do jornalismo de divulgar informações, bem apuradas e com fundamentação, às pessoas, principalmente em um caso como o de uma epidemia. Pois, até então, era uma doença que ninguém conhecia e que surge com tantas informações.

\section{REFERENCIAL TEORICO}

\subsection{Zika Vírus e Epidemia}

O Zika é um vírus transmitido pelo Aedes aegypti e possui uma longa história desde a sua descoberta. Mas, de fato, ele voltou ao século XXI, causando muitos problemas a homens, mulheres e crianças. Segundo Diniz (2016), em Zika do sertão nordestino à ameaça global, o vírus Zika recebe este nome devido à floresta onde foi identificado, em Uganda, na África. $\mathrm{Na}$ língua luganda, do idioma bantu, zika significa "coberto de ervas" ou "muito crescido".

A doença apresenta características semelhantes às da dengue, mas os médicos identificaram que a febre dos pacientes era forte, mas passava rápido, como também as manchas no corpo, que alguns pensaram ser apenas uma alergia (DINIZ, 2016, p. 41). Devido às desconfianças, as pesquisas foram iniciadas. Muito se demorou para encontrar uma doença que possuía esses sintomas.

O vírus voltou no século XXI, mais precisamente entre final de 2014, quando se iniciaram as suspeitas, a 2015, quando pesquisas iniciais apontavam o vírus e os problemas que ele estava causando.

O primeiro anúncio feito pela imprensa, confirmando o novo vírus, foi feito em 14 de maio de 2015, por meio de uma coletiva de imprensa. A partir daí o jornalismo começou uma saga em busca de informações sobre a doença. Pesquisadores e médicos se tornam fontes 
importantíssimas no assunto. E o fato que chamou a atenção pela febre Zika foi a microcefalia dos fetos, como seria o combate ao mosquito e quais seriam as garantias das mulheres afetadas e o futuro dessas crianças.

As entrevistas semiestruturadas foram feitas com uma população de cinco mulheres, distribuídas em três categorias: mulheres que optaram por adiar os planos de ter filho, mulheres que ficaram grávidas no segundo semestre de 2015 e primeiro semestre de 2016, mas continuaram a gestação e mulheres que tiveram um bebê com microcefalia. Por causa dos números baixos de casos no DF, para a pesquisa foi ampliado o espaço para, também, mulheres das regiões do entorno: Águas Lindas (GO), Valparaíso (GO) e Luziânia (GO ${ }^{2}$.

A princípio, não foram definidas classes sociais, etnias e nem um outro fator para a escolha dessas mulheres. Pois se entende que todas elas, independentemente da dificuldade financeira ou não, passaram por sentimentos semelhantes e grandes tomadas de decisões; sendo o objetivo da pesquisa a identificação dos sentidos e consciência de cada entrevistado sobre os ambientes e riscos, a partir do noticiário.

O documentário chamado Zika, realizado pela pesquisadora Débora Diniz, mostra os casos de cinco mulheres que tiveram alguma relação com o vírus, todas gestantes ou que recém perderam o filho para a doença. O documentário serviu como objeto para o trabalho da pesquisadora Mônica Mourão Lara Neto, chamado Zika pela voz das mulheres. Nesta pesquisa ela traz um assunto importante: o acesso às informações que essas mulheres tiveram e a necessidade de dar voz a essas que foram as personagens principais do caso, no interior da Paraíba, sobre a epidemia:

\footnotetext{
O documentário revela também o quão precárias e desencontradas são as informações sobre a síndrome congênita do Zika [...] Se essas mulheres não recebem informações adequadas sobre a sua saúde, tampouco podem contar com a assistência do Estado após o nascimento de seus filhos e filhas [...], portanto, a necessidade de as mulheres serem vistas como sujeitos plenos de direitos no contexto da epidemia do vírus Zika e, para tanto, devem ser ouvidas, devem ter suas vozes entendidas como capazes de produzir e legitimar o discurso sobre a emergência sanitária na mídia (NETO, 2016, p. 3).
}

Em Políticas e Sistemas de Saúde no Brasil, Giovanella (2012) define saúde não como apenas ausência de doença, mas como um processo que envolve aspectos epidemiológicos, socioeconômicos, ambientais, demográficos e culturais, ou seja, toda uma conjuntura social.

A região mais afetada pelo Zika vírus foi a região Nordeste (DINIZ, 2016, p. 133), devido a fatores como saneamento e infraestrutura, mas o estado do Rio de Janeiro também

\footnotetext{
${ }^{2}$ Entorno do DF é o jargão para a região metropolitana, assim como: ABC Paulista ou Grande São Paulo. 
possuiu um grande número de casos, segundo boletim do Ministério da Saúde divulgado no dia 26 de março de 2016, que cobre o período de 3 de janeiro a 2 de abril, a região possui mais de 25.930 notificações de casos prováveis, talvez mais pela questão da área verde do que de saneamento, já que se trata de uma região mais favorecida socialmente, economicamente. Porém, no Distrito Federal os casos foram bem pequenos em relação a outros lugares, como é apresentado no mapa abaixo:

Figura 1 - Semana Epidemiológica 45/2015 até a Semana Epidemiológica 52/2016

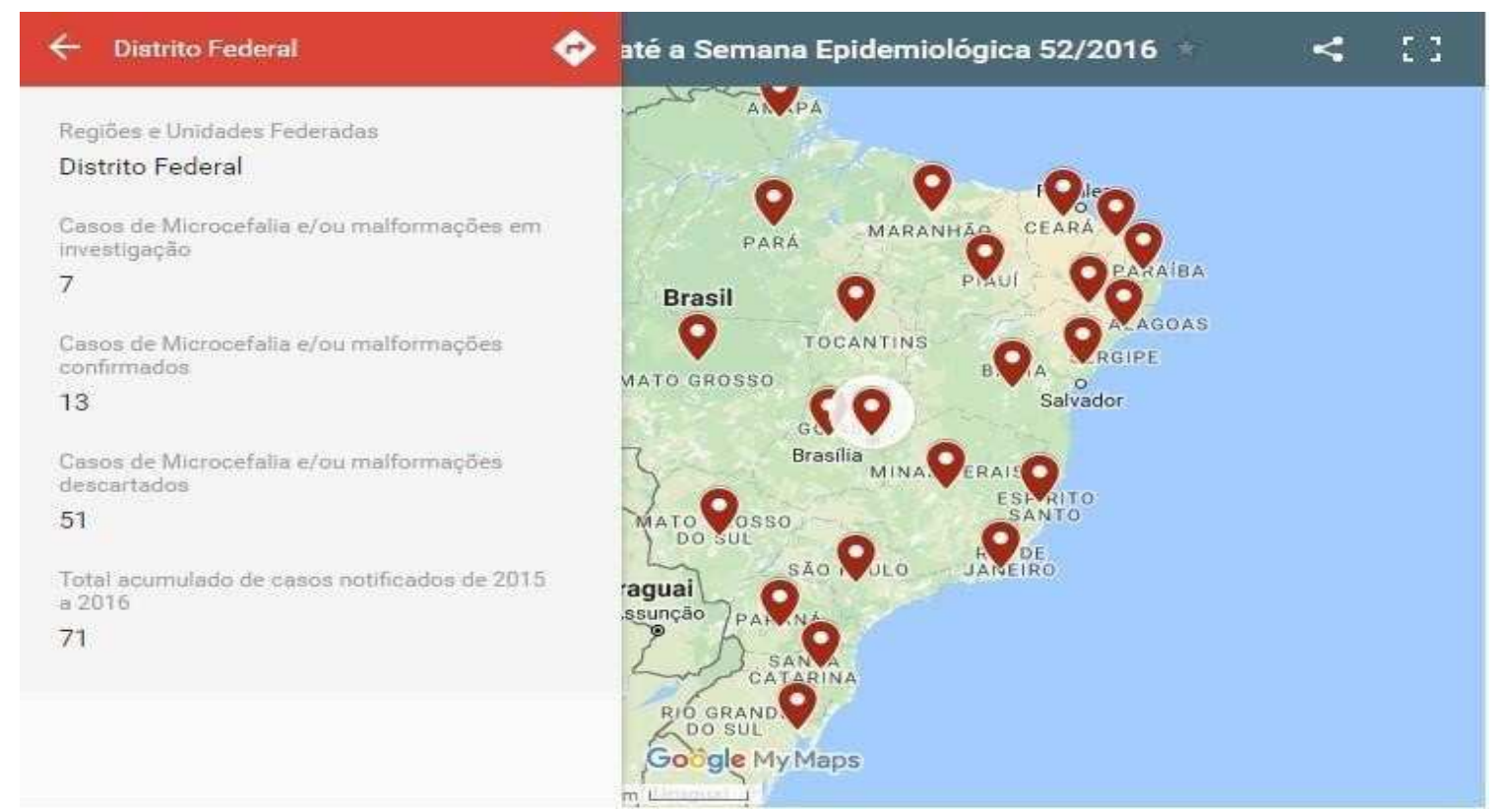

Fonte: Ministério da Saúde, 2016, p. 1

Foi em maio de 2015 que apareceram os primeiros indícios do vírus Zika. No início, o Ministério da Saúde (MS) declarou que o fato não apresentava maiores riscos, pois a doença não poderia ser tão grave como a dengue. Mas em outubro de 2015, o vírus passou a ser uma grande ameaça, quando foi associado aos casos de microcefalia em Pernambuco.

Conforme o informe epidemiológico do MS, até 31 de dezembro de 2016 (SE 52), em todo Brasil, 10.867 casos de microcefalia foram notificados no Registro de Eventos em Saúde Pública, segundo as definições do Protocolo de Vigilância (recém-nascido, criança, natimorto, abortamento ou feto). Desses, $3.183(29,3 \%)$ casos permanecem em investigação e 7.684 $(70,7 \%)$ casos foram investigados e classificados, sendo 2.366 confirmados, 49 prováveis e 5.269 descartados (ver Tabela 1). 
Tabela 1 - Distribuição acumulada dos casos notificados de microcefalia e/ou alterações do Sistema Nervoso Central (SNC), segundo definições do Protocolo de Vigilância

$(08 / 12 / 2015$ a 31/12/2016).

\begin{tabular}{|c|c|c|c|c|c|c|c|}
\hline \multirow[t]{2}{*}{$\mathrm{Ne}$} & \multirow{2}{*}{$\begin{array}{l}\text { REGIŌES E UNIDADES } \\
\text { FEDERADAS }\end{array}$} & \multicolumn{2}{|c|}{$\begin{array}{l}\text { Total acumulado }{ }^{1} \text { de } \\
\text { casos notificados de } 2015 \\
\text { a } 2016\end{array}$} & \multicolumn{4}{|c|}{$\begin{array}{l}\text { Casos notificados de Microcefalia e/ou Alteraçōes do } \text { SNC }^{2} \text {, sugestivos de } \\
\text { infecção congênita, em fetos, abortamentos, natimortos ou recém-nascidos }\end{array}$} \\
\hline & & $\mathbf{N}$ & $\%$ & $\begin{array}{l}\text { Permanecem em } \\
\text { investigaçăo }\end{array}$ & $\begin{array}{l}\text { Investigados e } \\
\text { confirmados }^{3}\end{array}$ & $\begin{array}{c}\text { Investigados e } \\
\text { prováveis }\end{array}$ & $\begin{array}{l}\text { Investigados e } \\
\text { descartados }^{4}\end{array}$ \\
\hline & BRASIL & 10.867 & 100 & 3.183 & 2.366 & 49 & 5.269 \\
\hline 1 & ALAGOAS & 376 & 3,5 & 51 & 90 & 0 & 235 \\
\hline 2 & BAHIA & 1.534 & 14,1 & 611 & 433 & 2 & 488 \\
\hline 3 & CEARÁ & 642 & 5,9 & 153 & 152 & 0 & 337 \\
\hline 4 & MARANHĀO & 328 & 3,0 & 83 & 160 & 0 & 85 \\
\hline 5 & PARAÍBA & 933 & 8,6 & 180 & 191 & 3 & 559 \\
\hline 6 & PERNAMBUCO & 2.259 & 20,8 & 325 & 408 & 0 & 1.526 \\
\hline 7 & PIAUI & 200 & 1,8 & 12 & 100 & 0 & 88 \\
\hline 8 & RIO GRANDE DO NORTE & 481 & 4,4 & 107 & 142 & 0 & 232 \\
\hline \multirow[t]{2}{*}{9} & SERGIPE & 270 & 2,5 & 58 & 128 & 0 & 84 \\
\hline & NORDESTE & 7.023 & 64,6 & 1.580 & 1.804 & 5 & 3.634 \\
\hline 10 & ESPIRITO SANTO & 265 & 2,4 & 98 & 36 & 9 & 122 \\
\hline 11 & MINAS GERAIS & 303 & 2,8 & 260 & 19 & 0 & 24 \\
\hline 12 & RIO DE JANEIRO & 861 & 7,9 & 399 & 179 & 0 & 283 \\
\hline \multirow[t]{2}{*}{13} & SÃO PAULO & 895 & 8,2 & 343 & 64 & 35 & 453 \\
\hline & SUDESTE & 2.324 & 21,4 & 1.100 & 298 & 44 & 882 \\
\hline 14 & ACRE & 52 & 0,5 & 13 & 2 & 0 & 37 \\
\hline 15 & AMAPA & 18 & 0,2 & 2 & 11 & 0 & 5 \\
\hline 16 & AMAZONAS & 63 & 0,6 & 23 & 26 & 0 & 14 \\
\hline 17 & PARÁ & 115 & 1,1 & 95 & 8 & 0 & 12 \\
\hline 18 & RONDÔNIA & 46 & 0,4 & 17 & 12 & 0 & 17 \\
\hline 19 & RORAIMA & 32 & 0,3 & 5 & 13 & 0 & 14 \\
\hline \multirow[t]{2}{*}{20} & TOCANTINS & 224 & 2,1 & 84 & 20 & 0 & 120 \\
\hline & NORTE & 550 & 5,1 & 239 & 92 & 0 & 219 \\
\hline 21 & DISTRITO FEDERAL & 70 & 0,6 & 6 & 13 & 0 & 51 \\
\hline 22 & GOIAS & 239 & 2,2 & 73 & 47 & 0 & 119 \\
\hline 23 & MATO GROSSO & 351 & 3,2 & 135 & 57 & 0 & 159 \\
\hline \multirow[t]{2}{*}{24} & MATO GROSSO DO SUL & 56 & 0,5 & 6 & 28 & 0 & 22 \\
\hline & CENTRO-OESTE & 716 & 6,6 & 220 & 145 & 0 & 351 \\
\hline 25 & PARANÁ & 56 & 0,5 & 8 & 3 & 0 & 45 \\
\hline 26 & RIO GRANDE DO SUL & 181 & 1,7 & 34 & 18 & 0 & 129 \\
\hline \multirow[t]{2}{*}{27} & SANTA CATARINA & 17 & 0,2 & 2 & 6 & 0 & 9 \\
\hline & sut & 254 & 2,3 & 44 & 27 & 0 & 183 \\
\hline
\end{tabular}

Fonte: Ministério da Saúde, 2016, p. 1

Para chegar às conclusões dessa pesquisa, foi escolhido o método de entrevista semiestruturada para que fosse possível compreender a recepção dessas informações pelas entrevistadas. Com isso, será possível questionar o jornalismo, a influência dos meios de comunicação, o agendamento midiático e as recepções por parte do público.

Para a construção deste trabalho, também foi utilizada a bibliometria que auxilia pesquisadores a conhecerem produções acadêmicas a respeito de um determinado assunto ou área, tornando-se uma pesquisa da disseminação e utilização dos estudos feitos e publicados (MARTINS, 2016. p. 04).

\section{A INFORMAÇÃO E A CONSCIENTIZAÇÃO A PARTIR DO NOTICIÁRIO}

Este trabalho se articula pelo fato de que as pessoas foram bombardeadas por várias informações sobre uma doença pouco conhecida, com isso se instalou um caos, pessoas 
preocupadas com todos os insetos, uma corrida às farmácias em busca de repelentes, uma mudança de rotina. Essas pessoas, mesmo as não afetadas exigiam respostas, sejam elas vindas pela mídia, pelos médicos ou cientistas.

No artigo Epidemia provocada pelo vírus Zika: informação e conhecimento, das pesquisadoras Débora Diniz e Luciana Brito, elas fazem uma nota sobre um dos primeiros casos de microcefalia registrado, a partir do documentário Zika. O caso relatado é do casal Joselito e Maria Carolina, pais de Maria Gabriela, criança afetada pelo vírus. Eles pouco sabem a respeito do problema da filha e cobram dos médicos, do Estado, da mídia e de cientistas conhecimento e informação.

\begin{abstract}
A história do casal é típica e singular. Maria Carolina engravidou sem planos de ampliar a família. No primeiro trimestre da gravidez, apresentou os sintomas do vírus Zika, mas foi diagnosticada pelo serviço de saúde da cidade como portadora de uma "virose". Na primeira ecografia, o médico suspeitou de alterações morfológicas no feto e solicitou exames adicionais para o diagnóstico de máformação. O casal os fez por conta própria, pois não eram oferecidos na rede pública de Esperança. Mas exames em sequência mostram contradições sobre o perímetro cefálico reduzido do feto (DINIZ; BRITO, 2016, p.3).
\end{abstract}

Logo, quando descobrem a má-formação congênita da filha, vão em busca de informações e é então que no vídeo cobram por seus direitos:

Joselito e Maria Carolina usam a linguagem dos direitos: negligência, acesso à informação, planejamento familiar, Lei 11.108 são alguns dos argumentos elencados na narrativa. Mas há um pedido original no texto familiar: "nós queremos o conhecimento de vocês (DINIZ; BRITO. 2016. p. 03)

O desconhecimento e a desinformação são um problema quando se refere à saúde, principalmente informações transmitidas na mídia de forma não adequada. Ainda no início, pouco se sabia sobre a doença, mas pouco foi apurado antes de ser anunciado pela imprensa. Essa falta de informações e conhecimento de todos os envolvidos pode induzir à distorção da informação, causando hábitos errôneos por parte dos receptores, no caso, a população afetada. Isso é afirmado em uma nota à imprensa, emitida no ano de 2016, pelo Ministério da Saúde 3

Consideramos importante o trabalho da imprensa, com seus questionamentos e críticas. Quando feita de maneira adequada, contribui para o controle social e correção das ações do poder público. A indução ao erro e o reforço a boatos, em uma situação de emergência nacional em saúde pública, no entanto, traz insegurança e confunde a população (MINISTÉRIO DA SAÚDE, 2016, p.01).

\footnotetext{
${ }^{3}$ Informações sobre o Boletim Epidemiológico de Microcefalia. Disponível em:<http://portalsaude.saude.gov.br/index.php/cidadao/principal/agencia-saude/22367-informacoes-sobre-oboletimepidemiologico-de-microcefalia>. Acesso em: 14 de setembro de 2016.
} 
Como o Zika vírus, outras doenças causaram um surto no Brasil. Por exemplo, podemos citar a febre amarela que, no seu início, gerou o debate sobre vacinas, assim como a AIDS/HIV, fortemente questionada nos anos de 1980 e que até hoje é uma doença com muitos preconceitos devido às notícias da época e da falta de conhecimento dos órgãos públicos, que não conseguiam passar à frente dos veículos midiáticos para transmitir as informações corretas. Como estas temos também: a dengue, o câncer e a crise do vírus Ebola, que foi e é apresentado pela mídia como ameaça à humanidade, o que contribuiu para propagar na sociedade apreensão e medo. O Zika é mais um que entra nessa lista. A pesquisadora Graça Castelo Branco, escreveu um artigo sobre a Evolução histórica do Conceito de Comunicação e Saúde. Segundo ela, algumas doenças da década de 1980 ajudaram no desenvolvimento da relação entre Comunicação e Saúde:

[...] a partir da década de 80 , com a propagação da SIDA e a necessidade de realizar acções e campanhas educativas mais adequadas, o que provocou um incremento no número e na qualidade de novos materiais educativos, tendo como objectivo uma comunicação mais eficaz. Posteriormente, problemas como a encefalopatia espongiforme bovina (BSE), a síndrome respiratória aguda grave (SARS), a gripe das aves (H5N1) e, mais recentemente, a gripe A (H1N1), que obtiveram grande atenção por parte dos meios de comunicação social, mobilizando indivíduos e populações inteiras, assumiram importância fundamental no desenvolvimento da comunicação em saúde (BRANCO, 2011, p. 190).

No caso do Zika vírus, os principais meios de comunicação eram a TV e a Internet. Mesmo assim, segundo uma pesquisa realizada pelo Instituto Patrícia Galvão ${ }^{4}$, a maioria dessas mulheres preferiam as orientações médicas. A pesquisa informa que três em cada quatro mulheres procuram se informar sobre a doença. Mesmo que a internet com $84 \%$ e a TV com $71 \%$ sejam os principais meios de informação, $47 \%$ das entrevistadas consideram que os médicos que fazem o acompanhamento na gravidez são a melhor forma de se informar sobre cuidados com o Zika vírus.

Pode se inferir que a atualização dos médicos em relação aos avanços científicos, meios de prevenção e tratamento da doença é uma demanda fundamental. Da mesma forma, a difusão de informações qualificadas pela mídia tem uma grande importância no enfrentamento à epidemia.

\footnotetext{
${ }^{4}$ Fundado em 2001, o Instituto Patrícia Galvão é uma organização social sem fins lucrativos que atua nos campos do direito à comunicação e dos direitos das mulheres brasileiras. Para o Instituto, a mídia é um espaço estratégico de incidência social e política para qualificar os debates sobre políticas públicas voltadas à promoção da igualdade e equidade de gênero.
} 


\title{
3 METODOLOGIA
}

Para analisar as informações recebidas pelas mulheres, objeto de estudo deste trabalho, foi utilizado o método de entrevista semiestruturada, pois desta maneira foi possível perceber como cada mulher se sentiu em relação às informações passadas pelos diversos veículos.

Com os primeiros casos, principalmente do elevado número de crianças com microcefalia, uma série de notícias surgiram com especulações, certezas, informativos e resultados de pesquisas de uma forma muito rápida. Essa sequência de informações pode levar às pessoas a insegurança e a desinformação, pois acabam não conseguindo filtrar o que lhes é emitido e ou repassando informações sem que elas sejam verdadeiras.

As entrevistas foram realizadas entre os dias 8 e 19 de maio de 2017. Como já no período dessas entrevistas, os conflitos políticos e econômicos do país estavam em alta escala nas agendas midiáticas, pouco ou quase nada se fala do vírus. Isso mudou, por um curto período, com o informativo do fim do alarde da doença, no dia 11 de maio de $2017^{5}$ :

\begin{abstract}
O Ministério da Saúde declarou, nesta quinta-feira (11), o fim da Emergência Nacional em Saúde Pública por conta do Zika vírus e sua associação com a microcefalia e outras alterações neurológicas. O número de registros da infecção caiu cerca de $95 \%$ nos primeiros meses deste ano em comparação com o mesmo período de 2016. Portanto, o Brasil não preenche mais os requisitos exigidos para manter o estado de emergência (PORTAL BRASIL, 2017).
\end{abstract}

Foram escolhidas cinco participantes. Todas mulheres. O motivo da escolha apenas pelo gênero feminino deu-se pela percepção de que elas são as mais afetadas com a doença tanto na saúde física como na psicológica.

Segundo um boletim divulgado pelo Ministério da Saúde, no dia 10 de novembro de 2016 dos 196.976 casos prováveis de infecção pelo Zika notificados no país até agosto de 2016, 16.264 foram em mulheres grávidas, sendo 10.325 confirmados.

Os dados mostram que a infecção pelo vírus Zika, em 2016, foi mais frequente em mulheres do que em homens e que a faixa etária dos casos em mulheres foi de 20 a 39 anos. Do total de casos, $67,3 \%$ foram em mulheres dos quais $72,8 \%$ em idade fértil.

\footnotetext{
5 Portal Brasil, com informações do Ministério da Saúde. Disponível em $:<$ http://www.brasil.gov.br/saude/2017/05/ministerio-da-saude-declara-fim-da-emergencia-nacional-para-zika>. Acesso em 18 de maio de 2017.
} 
O último episódio de saúde pública com semelhante impacto para as mulheres havia sito a epidemia da rubéola nos anos 1960. A rubéola em mulheres grávidas pode apresentar risco de $90 \%$ de alterações no feto se a infecção ocorrer nas primeiras dez semanas de gestação (DINIZ, 2016, p. 120).

Para a pesquisa, as participantes entrevistadas possuíam idades entre 23 e 37 anos.

Elas foram encaixadas nos seguintes perfis:

Tabela 3 - Divisão das entrevistadas

\section{Entrevistas Semiestruturadas}

\begin{tabular}{cc}
\hline Caracterização das Entrevistadas & Residente em: \\
\hline Duas mulheres (A e B) que adiaram os planos de terem o primeiro filho \\
devido ao vírus & $\begin{array}{c}\text { Samambaia - DF } \\
\text { Águas Claras - } \\
\text { novembro de 2016 }\end{array}$ \\
\hline Duas mulheres (C e D) que estavam grávidas entre outubro de 2015 e & Águas Lindas - \\
Uma mulher (E) afetada pelo vírus Zika que teve um bebê com & GO \\
microcefalia & Taguatinga - DF \\
\hline
\end{tabular}

Fonte: tabela elaborada pelos autores

As entrevistas foram feitas através de duas plataformas: Skype e Facetime. Apenas uma das entrevistadas (E) teve a disponibilidade de receber a pesquisadora em casa, o que foi de grande proveito, já que ela é uma das que mais buscou informações a respeito do vírus devido ao fato de ter tido um bebê afetado.

Elas responderam a um questionário feito com base em alguns polos temáticos criados para avaliar a situação de cada público quando apresentados ao Zika vírus:

Tabela 4 - Públicos e polos temáticos das perguntas.

\begin{tabular}{cc}
\hline PÚBLICOS & POLOS TEMÁTICOS DAS PERGUNTAS \\
\hline \multirow{2}{*}{ A e B } & Informacional e comunicacional \\
\cline { 2 - 2 } & Pré-planejamento familiar \\
\hline & Após alarde da epidemia \\
\hline Emocional para decisões \\
\hline Informacional e comunicacional \\
Paciente Assistida (orientação de médicos e
\end{tabular}




\begin{tabular}{c}
\hline C e D \\
\cline { 2 - 2 } $\begin{array}{c}\text { especialistas) } \\
\text { Sem planejamento ou com planejamento familiar } \\
\text { Sensação de alívio }\end{array}$ \\
\hline Informacional e comunicacional \\
Emocional para decisões - Trauma inicial \\
Paciente Assistida (orientação de médicos e \\
especialistas) \\
Pós-planejamento pessoal e familiar
\end{tabular}

Fonte: tabela elaborada pelos autores

No polo Informacional e comunicacional, as entrevistadas foram questionadas sobre o que elas conseguiram absorver do que liam, ouviam e ou assistiam sobre o tema e quais conclusões elas tiravam. No polo pré-planejamento familiar, foi analisado todo o processo de planejamento das entrevistadas A e B antes do alarde da doença e depois foi analisado o que elas passaram a planejar após o alarde da epidemia. Em emocional para decisões, a avaliação era o de como essas mulheres se prepararam emocionalmente para tomar a decisão de adiar a gravidez por um tempo até então indeterminado.

Para o público $\mathrm{C}$ e $\mathrm{D}$, também foi questionável o polo informacional $\mathrm{e}$ comunicacional. Depois foram os fatores de ansiedade e risco, pois nesse perfil elas estavam grávidas e ainda tinham o risco de serem afetadas pela doença. Com isso, havia uma ansiedade para se saber se o bebê nasceria ou não com os problemas gerados pela doença. Esse perfil foi o que teve mais apoio médico do que o primeiro, pois as gestantes estavam em processo de exames pré-natal e foram assistidas por médicos. Nesse caso, a análise é válida por saber o que essas futuras mães tinham de informações vindas pelos médicos.

Em seguida, é apresentado o polo de sem planejamento ou com planejamento familiar, pois cada mulher planejou ou não ter o bebê no período em destaque desse trabalho. Isso é importante para verificar os valores familiares e a preparação para enfrentar uma primeira gravidez sobre o risco de ter uma doença prejudicial ao bebê e à gestora. Por fim, vem a sensação de alívio dessas mães no nascimento de seus filhos, que será apresentada ao longo do trabalho.

No perfil da entrevista E, a que foi afetada pela doença, a principal análise é sobre as decisões que ela teve ao saber que teria uma criança com microcefalia, se ela pensou por 
exemplo em um possível aborto e qual foi a sensação pós-parto e a vida atual. Se ela se arrepende, se teve boas orientações médicas e o que sentiu com as informações midiáticas.

A partir da entrevista, algumas outras perguntas foram elaboradas e foram se alterando de acordo com as respostas das entrevistadas. Para o início da entrevista, lhes foi solicitado que se apresentassem com nome completo, idade, estado civil e profissão, com o objetivo de conhecer um pouco mais as entrevistadas. Depois, lhes fora questionado sobre o desejo de ser mãe:

A - "Eu sempre falei que queria engravidar aos 30, mas por causa de imprevistos da vida, eu já estou fazendo 32 anos e ainda não engravidei”.

B - "A vontade, mesmo, de ser mãe surgiu logo quando eu casei, principalmente por agora que tenho condições financeiras de ter filhos".

C - "Sempre tive vontade de ser mãe. Era um sonho, desde a minha adolescência me lembro de querer muito ser mãe por gostar muito de criança".

D - "Eu já casei com muita vontade de ser mãe. Sempre tive vontade de ser mãe, então logo quando eu casei parei de usar métodos contraceptivos porque eu esperava engravidar assim que Deus quisesse. E assim foi, depois de 3 meses de casada eu fiquei grávida, logo no período de maior "burburinho" do Zika".

E - "Eu não tinha vontade de ter filho. Depois que eu mudei para Brasília que eu conheci meu marido foi que a gente tentou por dois anos e quando resolvemos não tentar mais ter filhos, meu marido acabou fazendo a vasectomia, só que duas semanas depois do procedimento eu descobri que estava grávida de três semanas".

Todas as perguntas seguintes foram direcionadas a informações que elas buscaram ou receberam de veículos de comunicação, como internet, TV, rádio ou de vizinhos, amigos, familiares ou desconhecidos, além de especialistas como os médicos. Questionadas sobre por que meios elas receberam ou buscaram informações e se sentiram satisfeitas (informadas) sobre o que leram ou ouviram, responderam:

B - "Eu via que tinha muita gente falando disso na internet, até que eu assistindo um dia um jornal na TV, acho que era até o Jornal Nacional. Aí quando eu vi a quantidade de casos lá no Nordeste busquei ler algumas coisas na internet, principalmente em sites de saúde".

C - "Eu fiquei sabendo do caso do Zika pela TV. Os jornais mostravam o tanto de casos de crianças que estavam nascendo com microcefalia, que foi quando descobriram que isso era por causa do mosquito, logo em seguida eu descobri que estava grávida, então eu fiquei muito preocupada. As pessoas sempre me perguntavam "por que você vai engravidar agora?" Não foi algo planejado e as pessoas não entendiam isso".

D - "Como estava no auge de tudo, com os bebês com microcefalia que era por causa do mosquito pela TV, eu fiquei com muito medo. Foi assim que eu comecei a 
ler muito pela internet, ver programas na televisão e tirar dúvidas com a médica que estava me acompanhando na gestação".

E - "Todo mundo falava de Zika. Eu não gosto de assistir telejornal, prefiro ler notícias na internet e meus amigos do Facebook estavam compartilhando coisas sobre o vírus. Mas eu só me preocupei quando fiquei grávida, pois foi um susto, foi nada planejado. Só no $5^{\circ}$ mês, na morfológica de 22 de semanas que eu descobri que o Rafa viria com a má-formação".

A entrevistada A, teve Zika meses antes do planejado para engravidar, esse foi o principal motivo que a fez inicialmente buscar informações:

A - "A gente tem conhecimento dos sintomas pela mídia querendo ou não. Um dia eu amanheci com o rosto e o corpo todo empolado. E aí eu marquei uma consulta de emergência com a minha médica. Foi assim que descobri que era Zika, mas nem passou pela minha cabeça que fosse a doença, mesmo eu lendo sobre na internet todos os dias".

Quando questionadas sobre como elas receberam as informações de uma doença que pouco se tinha conhecimento, as entrevistadas ACDE responderam que se sentiram satisfeitas, mesmo com poucos detalhes das reportagens da televisão e das matérias disponíveis na internet e que procuraram um médico. A entrevistada B respondeu:

B - “Como eu não estava doente e já tinha há alguns meses ido ao médico para saber se eu podia engravidar, não achei que tinha necessidade ir ao médico só pra perguntar sobre Zika. O que vi na televisão já foi suficiente para adiar o plano de ter um bebê".

Pode-se observar, então, que as mulheres afetadas pelo Zika, seja pela doença sem estar grávida como no caso da entrevistada A, as grávidas $\mathrm{C}$ e D e, claro, a $\mathrm{E}$, foram assistidas por um especialista e ele servia como fonte para tirar dúvidas.

As entrevistadas A, B e D tiveram a oportunidade de se planejarem, seja para adiar a gravidez ou dar continuidade à gestação com atenção e cuidados. O planejamento é importante, pois evita possíveis riscos e que o bebê seja afetado, o que não gera $100 \%$ de certeza, já que a entrevistada $\mathrm{C}$, mesmo não tendo planejado a gravidez, não foi afetada, diferentemente da entrevistada E. Assim, pode-se dizer que A e B tiveram a maior oportunidade de escolha.

Pós acontecimentos e alardes do vírus em grande escala, os planos dessas mulheres mudaram, algumas puderam ter a sensação de alívio, outras se mantiveram em observação contínua em relação à doença. Elas foram questionadas sobre sentimentos e futuros planos, pós alarde: 
A - "Para mim, como já havia sido adiado pela segunda vez, pois na primeira vez o adiamento foi por uma questão financeira mesmo e aí decidimos esperar. Daí a gente tinha programado, para parar de tomar remédio e engravidar no início do ano passado (2016), aí depois do carnaval eu tive a Zika. Eu achei muito ruim, mas meu marido achou foi bom porque ele ainda não queria. Eu fiquei muito frustrada. A minha médica me disse pra esperar mais uns 8 meses. Já passou esse tempo, mas agora a minha ideia é engravidar no final do ano, para ter mais tempo".

B - "Ainda tenho receio de ter filho, ainda mais porque meu marido nos últimos meses fez algumas viagens para o nordeste a trabalho e sei que o Zika pode ser transmitida por relações sexuais. Vamos esperar, talvez seja no final do ano ou no ano que vem, não sei ainda. A vontade segue a mesma, mas o medo continua né, não quero ser irresponsável".

C - "A sensação de alívio veio um pouco antes e um pouco depois. Antes, porque assim, você faz o ultrassom e os exames e o médico diz pra você que seu bebê está bem, que o cérebro dele está bem formado, mas mesmo assim você ainda fica com aquele pé atrás porque o que diz a mídia é que às vezes o cérebro da criança poderia estar do tamanho normal e a criança ainda ter microcefalia, então você fica muito preocupada. Então você tem que esperar a criança nascer para saber se ele vai ou não ter problema de visão, olfato, entre outras coisas. Então assim, o alívio veio quando eu peguei ela no colo e a médica disse que ela era super saudável".

D - "Eu engravidei em julho de 2015, bem na época de maior crise. Eu sabia que aqui em Brasília a doença não tinha meio que chegado ainda, mas eu me preocupei, fiquei usando repelente, evitava sair de casa e tal. Tanto que eu fiquei sabendo pela TV que o melhor repelente que tinha e que eu usava estava em falta, aí eu surtei. Mas assim, eu me cuidei ao extremo, ia toda semana no médico. Eu só fiquei assim aliviada quando eu ganhei ele e vi que estava tudo bem. E que mesmo que ele tivesse algum problema eu ficaria feliz, pois foi um presente de Deus. Mas até hoje eu uso repelente e faço todos que moram comigo usar também".

E - "Como eu soube ainda grávida, meu marido e eu tivemos tempo para pensar e nos preparar. Em nenhum momento eu pensei em não ter o bebê, então eu procurei outras mães que tiveram os filhos com microcefalia, me orientava, pesquisava coisas na internet e seu tinha dúvida perguntava para um médico lá do Recife. A nossa rotina aqui em casa mudou muito, mas não me arrependo de nada. Meu filho é uma bênção e veio pra me trazer alegria. O tratamento é muito caro, pois ele precisa de um fisioterapeuta, um terapeuta ocupacional, médico pediatra, mas eu ainda não quis recorrer a ajuda do governo, pois até hoje tenho uma vida muito corrida e feliz e não quero ter dores de cabeça por agora"

Diante das respostas apresentadas, é possível identificar que, mesmo em conflito com a doença, as informações lidas, vistas e ouvidas por essas mulheres serviram como alertas para o novo vírus. Para a entrevistada $\mathrm{B}$, as informações foram suficientes para uma decisão final de adiar a gravidez. Para a entrevistada A, ter a doença a fez procurar mais informações médicas para além dos portais de saúde, TV, rádio e outros meios, já que ela teve a doença ainda em planos de engravidar.

As entrevistadas C e D se informaram pelos veículos de comunicação de forma preventiva. Isto é, se atualizaram sobre novas pesquisas e formas de prevenir a doença no uso 
de repelentes, evitar sair de casa e outros, porém, como estavam em acompanhamento médico, tiraram suas dúvidas com eles e depositavam sua confiança nos especialistas. Mesmo com tudo isso, só tiveram o sentimento de alívio no nascimento dos filhos, quando perceberam que tudo estava normal.

A entrevistada E, pouco procurou informações sobre o vírus em veículos de comunicação, já que devido às circunstâncias não acreditava que ia engravidar mais, porém logo que soube da gravidez procurou um médico e se preveniu, buscando algumas informações na internet, mas apenas no $5^{\circ}$ mês de gestação descobriu a má-formação do filho. Os médicos passaram a ser seu único meio de informação verídica.

As informações transmitidas pela imprensa serviram como estalo inicial na percepção da doença para essas mulheres, foi por meio delas que foi possível saber um pouco mais sobre uma doença, mesmo não conseguindo filtrar o que era de fato comprovado, mas procurando se alertar. Apesar disso, elas não se conformaram com tudo e procuraram orientações médicas, procedimento normal, analisando cada situação em particular.

\section{CONSIDERAÇÕES FINAIS}

A comunicação e a saúde são duas áreas de estudo diferentes, mas que ao longo do tempo viram uma complementaridade. A comunicação nessa relação consolidou o poder de atuação na sociedade e a saúde encontrou um meio estratégico de circulação de informações.

Este trabalho reforça a necessidade de união entre essas duas áreas. Elas possuem potencialidades na busca de informar a população, pois é preciso que uma seja mais coerente com a outra e dividam as dúvidas, ideias e novidade, porque a questão principal não é só transmitir informação é trabalhar na construção do conhecimento. Isto é, desde o envolvimento com as pessoas em evitar doenças, até a busca por serviços a que os indivíduos têm direito e que não sabem por falta de informação.

O tema desta pesquisa enfrentou uma grande dificuldade ao longo do processo de desenvolvimento. $\mathrm{O}$ assunto Zika ainda é muito pouco falado no âmbito científico. Segundo a Secretaria de Vigilância Sanitária, em 2014 havia apenas 147 publicações sobre o Zika, atualmente são mais de mil. Mesmo que recentemente as pesquisas estejam começando a apresentar resultados satisfatórios, a mídia está indo contra esse fluxo, pois enquanto mais resultados aparecem, menos se fala da enfermidade, atualmente. Esse fluxo também dificultou o resgate de memórias para algumas das entrevistadas, que por causa do tempo entre o alarde da doença e as entrevistas não se recordavam muito de fatos pontuais. 
Como apresentado no trabalho, o Distrito Federal não teve tantos casos de pessoas afetadas pelo vírus, o que dificultou o recrutamento para as entrevistas, pois foi necessário abrir o leque para as regiões do entorno. A maior dificuldade foi a de encontrar uma mulher que se encaixasse no grupo da que tivesse sido afetada e tivesse filhos com a microcefalia, mas isso foi solucionado depois de uma busca pelas redes sociais e telefonemas. Outra questão é o fato de que todas elas ou são mães de bebês ou têm uma vida profissional muito corrida, o que fez a pesquisadora recorrer a recursos tecnológicos para poder ter a proximidade e alcançar as respostas para a análise dos resultados, com o uso do Skype e Facetime.

A partir do objetivo deste trabalho, que era analisar como as mulheres se sentiam em relação às informações transmitidas pelos veículos de comunicação, de forma ampla, isto é, se a partir delas se sentiram completamente informadas a respeito do assunto ou não, foi percebido que as pessoas conseguem filtrar os assuntos dos noticiários, de acordo com a sua realidade. As entrevistadas passaram durante o período de 2015 e 2016 por uma ameaça chamada Zika vírus, que naquele momento colocava em risco os planos dessas futuras mães. Por esse motivo, elas procuraram e se atentavam mais aos noticiários.

Durante o desenvolvimento da pesquisa, o fato do fim do alerta para a doença feito pelo Ministério da Saúde em conjunto com organizações sociais e de saúde fez com que a epidemia já não criasse mais tanto alarde como há dois anos. Sem dúvida, essa reviravolta causa a perspectiva de um futuro trabalho sobre o antes e o depois do alerta.

No presente trabalho foi verificado, também, que as entrevistadas, a partir de cada realidade, se mantinham satisfeitas com o que liam, ouviam e ou assistiam sobre a epidemia, mas a maioria procurou ajuda de um especialista para tirar possíveis dúvidas e saber como agir na situação apresentada.

Durante o processo de metodologia, a ação mais difícil, como citado anteriormente, foi o de resgate na memória dessas mulheres sobre algo que foi vivenciado há pouco mais de um ano. Algumas pela proximidade com a realidade (A, B, C e D) conseguem se lembrar um pouco de alguns fatos, mas para uma entrevista realizada tanto tempo depois dos fatos, esse resgaste de memórias é complicado, por isso foram desenvolvidos os polos de tensões, para uma verificação da conscientização a partir dos noticiários.

A entrevistada E conseguiu apresentar em suas respostas um resgate melhor, já que viveu intensamente a doença e convive até hoje com as causas. 
A Comunicação e Saúde vêm desenvolvendo uma relação que fomenta a comunidade científica e propicia, principalmente, por meio de estratégias comunicacionais, a tradução, em linguagem popular, acessível, dos significados específicos da área de Saúde.

Portanto, esse trabalho sugere que haja mais interação entre os ouvintes, a imprensa e os assuntos de saúde, ele vem propor que novas pesquisas na área de Comunicação e Saúde possibilitem abrangência e relevância para as duas áreas.

\section{REFERÊNCIAS}

AGUIAR, Raquel; ARAÚJO, Inesita Soares. A mídia em meio às 'emergências' do vírus Zika: questões para o campo da comunicação e saúde. Revista Eletrônica de Comunicação, Informação \& Inovação em Saúde, [S.1.], v. 10, n. 1, mar. 2016. ISSN 1981-6278. Disponível em: <https://www.reciis.icict.fiocruz.br/index.php/reciis/article/view/1088>. Acesso em: 15 abr. 2017.

ANTUNES, Michele Nacif et al. Arquivos visuais relacionados ao vírus Zika: imagens no Instagram como parte da constituição de uma memória da epidemia. Revista Eletrônica de Comunicação, Informação \& Inovação em Saúde, [S.1.], v. 10, n. 3, set. 2016. ISSN 19816278.

Disponível

em: <https://www.reciis.icict.fiocruz.br/index.php/reciis/article/view/1175>. Acesso em: 15 abr. 2017.

BRANCO, Graça Castelo. Evolução histórica do Conceito de Comunicação e Saúde. In. PLACIOS, Jatobá; SERRA, Paulo. PRAGMÁTICA: COMUNICAÇÃO PUBLICITÁRIA E MARKETING. Disponível em: <http://www.labcom-ifp.ubi.pt/book/27>. Acesso em $10 \mathrm{de}$ maio de 2017.

COESMICROCEFALIAS, Centro de operações de emergências em saúde pública sobre microcefalias. Informe Epidemiológico No 57 - Semana Epidemiológica (SE) 52/2016 (25 A 31/12/2016). Disponível em: <http://combateaedes.saude.gov.br/images/pdf/InformeEpidemiologico-n57-SE-52_201609jan2017.pdf>. Acesso em 10 abr. 2017.

Monitoramento Dos Casos De Microcefalia No Brasil. Registro de Eventos de Saúde Pública - RESP (dados atualizados até 31/12/2016 e extraídos em 06/01/2017). Disponível em: <http://combateaedes.saude.gov.br/images/pdf/InformeEpidemiologico-n57-SE-52_201609jan2017.pdf >. Acesso em 10 abr. 2017.

DINIZ, Debora. Zika: do Sertão nordestino à ameaça global. $1^{\text {a }}$ Ed. Rio de Janeiro: Civilização Brasileira, 2016. P. 192.

DINIZ, Debora. Zika: Documentário.Disponívelem: $<$ https://www.youtube.com/watch?v=j9tqt0jaoG0>. Acesso em: 15 de abr. 2017. 
DINIZ, Debora; BRITO, Luciana. Epidemia provocada pelo vírus Zika: informação e conhecimento. Revista Eletrônica de Comunicação, Informação \& Inovação em Saúde, [S.1.], v. 10, n. 2, jun 2016. ISSN 1981-6278. Disponível em: <https://www.reciis.icict.fiocruz.br/index.php/reciis/article/view/1148>. Acesso em: 15 abr. 2017.

GALVÃO, Instituto Patrícia. 90\% das grávidas querem testes para saber se tiveram zika e 70\% demandam maior acesso a ultrassons. Disponível em: < http://agenciapatriciagalvao.org.br/direitos-sexuais-e-reprodutivos/90-das-gravidasqueremtestes-para-saber-se-tiveram-zika-e-70-demandam-maior-acesso-ultrassons/>. Acesso em 18 de maio de 2017.

GIOVANELlA L; ESCOREL S; et.al (Orgs.) Organizadores. Políticas e sistemas de saúde no Brasil. $2^{\text {a }}$ Ed. Rio de Janeiro: Editora Fiocruz/Centro Brasileiro de Estudos de Saúde; 2012.

NETTO, Mônica Mourão Lara. Zika pela voz das mulheres. Revista Eletrônica de Comunicação, Informação \& Inovação em Saúde, [S.1.], v. 10, n. 3, set. 2016. ISSN 19816278.

Disponível

em: <https://www.reciis.icict.fiocruz.br/index.php/reciis/article/view/1176>. Acesso em: 15 abr. 2017.

MARTINS, Maria de Fátima Moreira. Análise bibliométrica de artigos científicos sobre o vírus Zika. Revista Eletrônica de Comunicação, Informação \& Inovação em Saúde, [S.l.], v. 10, n. 1, mar. 2016. ISSN 1981-6278. Disponível em: <https://www.reciis.icict.fiocruz.br/index.php/reciis/article/view/1096>. Acesso em: 15 abr. 2017.

MINISTÉRIODASAÚDE. Mapa de Casos de Microcefalia divulgado pelo portal do Ministério da $\quad$ Saúde. $\quad$ Disponível em:< http://combateaedes.saude.gov.br/pt/situacaoepidemiologica>. Acesso em 10 abr. 2017.

\section{Como Referenciar este Artigo, conforme ABNT:}

L. B. SIQUEIRA, R. B. DIAS, L. M. A. SILVA, V. M. V. B. SOUSA, E. M. LACERDA Comunicação e Saúde: Uma Análise Comunicacional do Enfrentamento do Zika Vírus por Potenciais Gestantes do Distrito Federal e Entorno. Rev. FSA, Teresina, v.19, n. 1, art. 4, p. 58-76, jan. 2022.

\begin{tabular}{|l|c|c|c|c|c|}
\hline \multicolumn{1}{|c|}{ Contribuição dos Autores } & $\begin{array}{c}\text { L. B. } \\
\text { Siqueira }\end{array}$ & $\begin{array}{c}\text { R. B. } \\
\text { Dias }\end{array}$ & $\begin{array}{c}\text { L. M. A. } \\
\text { Silva }\end{array}$ & $\begin{array}{c}\text { V. M. V. } \\
\text { B. Sousa }\end{array}$ & $\begin{array}{c}\text { E. M. } \\
\text { Lacerda }\end{array}$ \\
\hline 1) concepção e planejamento. & $\mathrm{X}$ & $\mathrm{X}$ & $\mathrm{X}$ & $\mathrm{X}$ & $\mathrm{X}$ \\
\hline 2) análise e interpretação dos dados. & $\mathrm{X}$ & $\mathrm{X}$ & $\mathrm{X}$ & $\mathrm{X}$ & $\mathrm{X}$ \\
\hline 3) elaboração do rascunho ou na revisão crítica do conteúdo. & $\mathrm{X}$ & $\mathrm{X}$ & $\mathrm{X}$ & $\mathrm{X}$ & $\mathrm{X}$ \\
\hline 4) participação na aprovação da versão final do manuscrito. & $\mathrm{X}$ & $\mathrm{X}$ & $\mathrm{X}$ & $\mathrm{X}$ & $\mathrm{X}$ \\
\hline
\end{tabular}

